\title{
Pleural Effusion Related to Chronic Hepatitis B Virus Reactivation: A Rare Association
}

\author{
Ana Oliveira ${ }^{1}$, Diana Valadares ${ }^{2}$, Felipe Nery ${ }^{2,3,4}$ \\ ${ }^{1}$ Serviço de Medicina Interna, Centro Hospitalar Universitário do Porto, Porto, Portugal \\ ${ }^{2}$ Unidade de Cuidados Intermédios Médicos, Serviço de Cuidados Intensivos, Centro Hospitalar Universitário do Porto, Porto, Portugal \\ ${ }^{3}$ Instituto de Ciências Biomédicas Abel Salazar, Universidade do Porto, Porto, Portugal \\ ${ }^{4}$ EpiUnit, Instituto de Saúde Pública da Universidade do Porto, Porto, Portugal
}

\section{Doi: 10.12890/2021_002270- European Journal of Case Reports in Internal Medicine - @ EFIM 2021}

Received: 05/01/2021

Accepted: $17 / 01 / 2021$

Published: $12 / 02 / 2021$

How to cite this article: Oliveira A, Valadares D, Nery F. Pleural effusion related to chronic hepatitis B virus reactivation: a rare association. EJCRIM 2021;8: doi:10.12890/2021_002270.

Conflicts of Interests: The Authors declare that there are no competing interests.

This article is licensed under a Commons Attribution Non-Commercial 4.0 License

\section{ABSTRACT}

Despite worldwide vaccination campaigns, hepatitis B virus (HBV) infection remains a major public health problem. The natural history ranges from asymptomatic infection to severe liver injury or failure, chronic complications or reactivation episodes. The effects of HBV on the organism are immunomediated, possibly triggering extrahepatic manifestations. Since 1971, only a few cases of pleural effusion related to HBV infection have been described. We report HBV-associated pleural effusion occurring during a viral reactivation episode. Antiviral treatment directed towards pleural effusion related to HBV infection should be dictated by underlying liver disease severity and not pleural effusion severity.

\section{LEARNING POINTS}

- In the presence of pleural effusion of unknown origin, especially if with simultaneous acute hepatitis, a viral aetiology should be suspected and pursued.

- The severity of liver disease and not the pleural effusion should guide antiviral treatment.

\section{KEYWORDS}

Hepatitis B virus, viral reactivation, extrahepatic manifestations, pleural effusion

\section{INTRODUCTION}

Hepatitis B virus (HBV) infection remains a major public health problem, being the tenth leading cause of death worldwide. It is estimated that $30 \%$ of the world's population has been exposed to HBV, with about 2 billion people infected and 240-400 million remaining chronic carriers ${ }^{[1,2]}$. Prevalence is estimated to be $0.9 \%$ in Europe and $1.45 \%$ in Portugal ${ }^{[3,4]}$. Its natural history ranges from acute infection that can present with no or mild hepatitis, to severe acute liver injury (ALI) or failure (ALF), to a chronic course that can lead to advanced liver disease ${ }^{[1]}$. Spontaneous or induced HBV reactivation can occur in $20-30 \%$ of patients with a quiescent chronic infection ${ }^{[1]}$. $\mathrm{HBs} \mathrm{Ag}$ seroclearance is the optimal outcome of HBV treatment, and can also occur spontaneously in some patients, but in either case is unusual[5].

HBV extrahepatic manifestations are immunomediated ${ }^{[1]}$. In 1971, the first case of pleural effusion associated with viral hepatitis (presumably B) was described ${ }^{[6]}$. Six years later, hepatitis antigens were identified for the first time in pleural fluid, confirming the likelihood of pleural effusion secondary to HBV infection ${ }^{[7]}$. However, although its real incidence is still unknown, this association is rarely reported nowadays. Pathogenesis is unclear, but there is probably an underlying immunological mechanism ${ }^{[8,9]}$. 
We present a case of pleural effusion accompanying reactivation of HBV chronic infection in a non-cirrhotic patient, which resolved along with liver recovery. Our main purpose is to promote awareness of HBV-related pleural effusion, so the clinician is aware of this possibility in the setting of pleural effusion of undetermined aetiology in patients with an appropriate clinical context.

\section{CASE DESCRIPTION}

A 52-year-old man presented to the emergency department with a 5-day history of upper abdominal pain, nausea and jaundice. On physical examination, he was afebrile, haemodynamically stable, jaundiced and had a palpable and painful liver edge. There were no clinical signs of encephalopathy. The patient had a history of risky sexual contact (unprotected heterosexual intercourse) years before. There was no history of parenteral drug use, blood transfusion, HBV infection or familial aggregation. At admission, blood analysis revealed aspartate aminotransferase (AST) 1,075 U/I, alanine aminotransferase (ALT) 2,716 U/I, alkaline phosphatase (ALP) $173 \mathrm{U} / \mathrm{l}$, total bilirubin (TB) 10.3 $\mathrm{mg} / \mathrm{dl}$, direct bilirubin (DB) $9.64 \mathrm{mg} / \mathrm{dl}$ and INR 1.24 (Table 1). Blood count, renal function and serum pancreatic enzymes were all within the normal range, and C-reactive protein was $14.9 \mathrm{mg} / \mathrm{l}$. Abdominal ultrasound showed a normal liver and no ascites. The HBV serological profile showed positivity for $\mathrm{HBsAg}, \mathrm{HBeAg}$, anti-HBe and anti-HBc (total and IgM); anti-HBs was negative; and the HBV viral load was 1,150,000 $\mathrm{IU} / \mathrm{ml}$. Hepatitis A, C, D and E virus, cytomegalovirus and human immunodeficiency viruses 1 and 2 were negative. Immunological study for autoimmune hepatitis was negative. The patient was admitted to the Medical Intermediate Care Unit.

The patient also had signs of large right-sided pleural effusion at admission, without any respiratory symptoms. Computed tomography of the thorax did not show any features of parenchymal disease. Pleural liquid was classified as an exudate (according to Light's criteria) with mononuclear predominance (1,822 polymorphonuclear and 2,957 mononuclear cells/ul); adenosine deaminase was $36 \mathrm{U} / \mathrm{I}(\mathrm{N}<20 \mathrm{U} / \mathrm{I})$ but Ziehl-Neelsen stain and mycobacteriological culture were negative, as was microbiological culture. No malignant cells were identified on anatomical pathological study and cytometry showed no evidence of a lymphoproliferative disorder. There was no clinical or serological evidence of current immunological disease. HBV DNA was identified in the pleural liquid (2,290 IU/ml). The patient developed an iatrogenic pneumothorax after diagnostic thoracentesis, which was treated conservatively.

The clinical scenario was interpreted as reactivation of a chronic HBV infection with associated pleural effusion. Best supportive care and a 5-day $\mathrm{N}$-acetylcysteine protocol were initiated. The patient never showed any signs of coagulopathy or encephalopathy, and bilirubin and aminotransferase levels progressively decreased, so no antiviral therapy was started. Pleural effusion also reduced without HBV antiviraldirected therapy or diuretics (Fig. 1). The patient was discharged home 16 days later, with AST 43 U/I, ALT 132 U/I, ALP 138 U/I, TB 1.53 mg/ $\mathrm{dl}$, DB $1.35 \mathrm{mg} / \mathrm{dl}$ and INR 1.08. After 6 months of follow-up, the patient had a completely normal liver profile. At this time, seroconversion of HBsAg (anti-HBs >1,000 IU/I) was documented with HBeAg turning negative (Table 1), liver stiffness (by transient elastography) was 6.1 $\mathrm{kPa}$ and there were no clinical signs of pleural effusion.

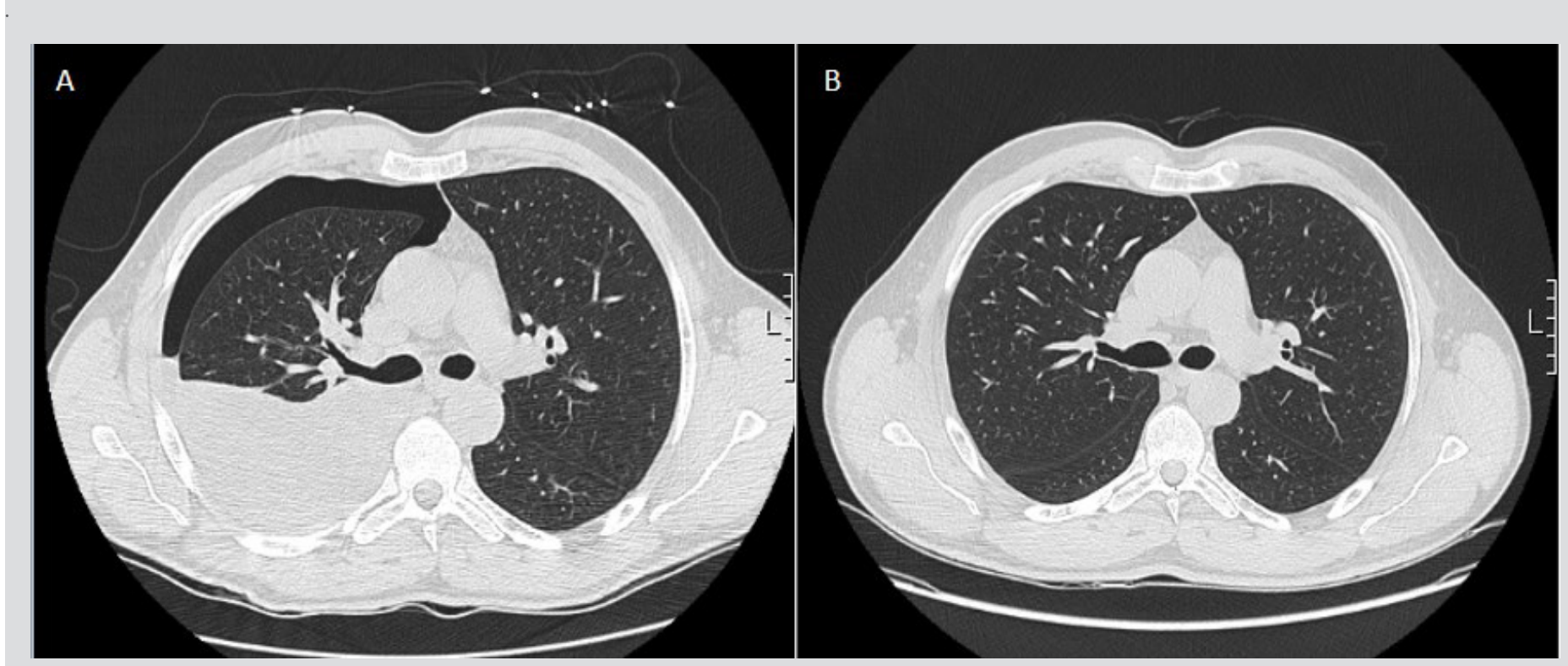

Figure 1. Evolution of pleural effusion, at day 10 (A, with iatrogenic pneumothorax) and 1 month later (B) 


\begin{tabular}{|c|c|c|c|c|c|c|c|}
\hline & Day 0 & Day 2 & Day 6 & Day 10 & Day 16 & At 1 month & At 6 months \\
\hline$T B, m g / d l$ & 10.32 & 10.22 & 4.7 & 2.7 & 1.53 & 0.92 & 0.38 \\
\hline$D B, m g / d l$ & 9.64 & 9.58 & 4.1 & 2.3 & 1.35 & & \\
\hline AST, U/l at $37^{\circ} \mathrm{C}$ & 1,075 & 578 & & 161 & 43 & 23 & 17 \\
\hline$A L T, U / I$ at $37^{\circ} \mathrm{C}$ & 2,716 & 1,468 & 749 & 410 & 132 & 41 & 15 \\
\hline$A L P, U / l$ at $37^{\circ} \mathrm{C}$ & 173 & 161 & 189 & 410 & 138 & 72 & 31 \\
\hline $\mathrm{GGT}, \mathrm{U} / \mathrm{lat} 37^{\circ} \mathrm{C}$ & & 306 & 406 & 391 & 304 & 189 & 18 \\
\hline INR & 1.24 & 1.26 & 1.11 & 1.17 & 1.08 & 1.10 & 1.01 \\
\hline HBsAg & + & & & & & & - \\
\hline Anti-HBs & - & & & & & & + \\
\hline Anti-HBc & + & & & & & & + \\
\hline HBeAg & + & & & & & & - \\
\hline Anti-HBe & + & & & & & & + \\
\hline Serum HBV viral load, IU/ml & $1,150,000$ & & & & & & Not detectable \\
\hline Pleural effusion & Large & & & Medium-large & & None & \\
\hline
\end{tabular}

Table 1. Evolution of laboratory parameters and volume of pleural effusion

ALP, alkaline phosphatase; ALT, alanine aminotransferase; AST, aspartate aminotransferase; DB, direct bilirubin; GGT, gamma-glutamyl transferase; TB, total bilirubin.

\section{DISCUSSION}

We report a rare association of pleural effusion secondary to HBV reactivation, without any other obvious cause after an extensive search; malignancy, pulmonary parenchymal disease, infection other than HBV, immunological or other inflammatory conditions, and pleural effusion related to liver cirrhosis, were all ruled out. In addition, it was possible to identify HBV virus in the pleural fluid, which resolved along with HBV serum clearance, making this direct association even more plausible. Importantly, hydrothorax associated with cirrhosis was also excluded, since in addition to hydrothorax being an exudate, cirrhosis was also ruled out as the patient presented with normal liver morphology on abdominal ultrasound together with a liver stiffness value compatible with FO/F1 (no or minimal fibrosis).

The association of pleural effusion with HBV infection is rarely reported, with only, to our knowledge, 14 cases previously described; of these, only two occurred during HBV reactivation ${ }^{[8-10]}$. Unlike our case, they occurred in the setting of severe hepatitis; even so, both patients had a good outcome without targeted therapy, as did our patient ${ }^{[8,9]}$. We propose that, in the setting of pleural effusion related to HBV infection, an accurate diagnostic aetiological work-up should be conducted with HBV viral load in pleural liquid also determined. Also, if no other cause for pleural effusion is identified, an HBV-associated aetiology must be assumed.

Extrahepatic manifestations of HBV infection are usually indications for antiviral therapy, however, given the rarity of this association, no recommendations have been published so far regarding pleural involvement. We propose that the severity of the underlying liver disease should dictate antiviral treatment in the setting of HBV-associated pleural effusion and not the severity of pleural effusion.

We also highlight two other rare events in our patient. First, spontaneous chronic HBV reactivation occurred with no identified underlying immunosuppressive condition. Second, spontaneous clearance of HBV infection after reactivation was seen. 
The patient did not fulfil any recognized criteria for implementing antiviral therapy ${ }^{[1]}$. Spontaneous clearance of HBsAg is commonly seen in acute infection, but not in cases of reactivation ${ }^{[5]}$. HBsAg loss is achieved by interferon therapy in less than $11 \%$ of patients, by nucleotide analogues in less than $5 \%$, and spontaneously in less than $2.5 \%{ }^{[2,11-13]}$. Only case reports have described spontaneous HBsAg seroconversion after reactivation flares ${ }^{[14,15]}$. Interestingly, one of the described patients also had pleural effusion associated with HBV infection ${ }^{[15]}$. The factors associated with HBsAg seroconversion, especially after chronic HBV reactivation, remain to be determined.

\section{REFERENCES}

1. Jindal A, Kumar M, Sarin SK. Management of acute hepatitis B and reactivation of hepatitis B. Liver Int 2013;33(1):164-175.

2. World Health Organization. Guidelines for the prevention, care and treatment of persons with chronic hepatitis B infection. Geneva: WHO; 2015.

3. European Centre for Disease Prevention and Control. Hepatitis B - annual epidemiological report for 2017. Solna, Sweden: ECDC; 2019.

4. Carvalhana SC, Leitão J, Alves AC, Bourbon M, Cortez-Pinto H. Hepatits B and C prevalence in Portugal: disparity between general population and high-risk groups. Eur J Gastroenterol Hepatol 2016:28(6):640-644.

5. European Association for the Study of the Liver. EASL 2017 Clinical Practice Guidelines on the management of hepatitis B virus infection. J Hepatol 2017;67:370-398.

6. Gross PA, Gerding DN. Pleural effusion associated with viral hepatitis. Gastroenterology 1971;60(5):898-902.

7. Tabor E, Russel RP, Gerety RJ, Barker LF, Hillis WD, Jackson DR. Hepatitis B surface antigen and e antigen in pleural effusion: a case report. Gastroenterology 1977;73:11571159.

8. Lee HS, Yang PM, Liu BF, Lee CL, Hsu HC, Su IJ, et al. Pleural effusion coinciding with acute exacerbations in a patient with chronic hepatitis B. Gastroenterology 1989;96:16041606.

9. Nail AMA, Gadour MOEH. Recurrent exsudative pleural effusion with flare up of chronic hepatitis B virus infection. Sudan JMS 2011;6(6):281-283.

10. Viola C, Vineta L, Bosch J, Rodés J. Exudative ascitis in the course of acute type B hepatitis. Hepatology 1983; ${ }^{3}(6): 1013-1015$.

11. Gish RG, Chang TT, Lai CL, de Man R, Gadano A, Poordad F, et al. Loss of HBsAg antigen during treatment with entecavir or lamivudine in nucleoside-naïve HBeAg-positive patients with chronic hepatitis B. J Viral Hepat 2010;17:16-22.

12. Liu J, Yang HI, Lee MH, Lu SN, Jen CL, Wang LY, et al. Incidence and determinants of spontaneous hepatitis B surface antigen seroclearance: a community-based follow-up study. Gastroenterology 2010;139:474-482.

13. Kobayashi M, Hosaka T, Suzuki F, Akuta N, Sezaki H, Suzuki Y, et al. Seroclearance rate of hepatitis B surface antigen in 2112 patients with chronic hepatitis in Japan during long-term follow-up. J Gastroenterol 2014:49:538-546.

14. Altinbas A, Yuksel I, Pamucku M, Ekiz F, Basar O, Yuksel O. Spontaneous HBsAg seroconversion after severe flare of chronic hepatitis B infection. Ann Hepatol 2010;9(2):194197.

15. Katsanos KH, Kitsanou M, Manatou K, Papathanasopoulos A, Chrisodoulou DK, Tsianos EV. Spontaneous HBsAg clearance in a patient with acute hepatitis B and pleural exudates. Ann Gastroenterol 2007;20(2):147-148. 
European Journal

of Case Reports in

Internal Medicine 